\title{
Identifying Keys to Win in the World Karate Championship
}

\author{
${ }^{1}$ Reza Seyedi, ${ }^{1}$ Yaping Zhong*(D), ${ }^{2}$ Siavash Khodaparast, ${ }^{1}$ Dominique Sigillo, \\ ${ }^{1}$ Ahad Azizi, ${ }^{1}$ Qu Yiming \\ ${ }^{1}$ Exercise Physiology and Training Department, Physical Education Faculty, Wuhan Sport University, \\ Wuhan, China. ${ }^{2}$ Department of Physical Education and Sports Science, Lahijan Branch, Islamic Azad \\ University, Lahijan, Iran.
}

Submitted 03 September 2020; Accepted in final form 25 October 2020.

\begin{abstract}
Background. Studies in this domain help focus on the techniques with high application to improve the point attainment, without providing points for the other opponents. Objectives. The purpose of this study was to analyze and investigate the most common scoring techniques used and the highest intensity competition times that have been fulfilled by the champions of the World Karate Leagues 2019 and the World Championship 2018. Methods. One hundred and eighteen karate competitions in 5 weight groups $(-60,-67,-75,-84$, and +84$)$ and from each weight rank, including 5 top-level athletes of the World Karate Federation ranking, were analyzed and studied. This study data were collated using Video Analyzer, Microsoft Excel, and SPSS, and the data were assessed using the Chi-square statistical tests $(\chi 2)$. Results. This study indicated that only $31.9 \%$ of total attacks fulfilled by the world champions were successful in gaining points, the last minute of competition was the highest intensity time in a three-minute competition (with $46.70 \%$ of attacks happening then), and the techniques of Ashi Barai and Gia Kuzuki were the most commonly used techniques among the techniques for scoring used by world champions. Conclusion. The coaches must develop new strategies during the training sessions and compare their athletes' techniques with those of the world elites to gain uniform endeavors and improve their athletes' performance to reach the level of world champions.
\end{abstract}

\section{KEYWORDS: Karate, World Championship, Competition, Scoring, Winning.}

\section{INTRODUCTION}

Karate is one of the martial arts with continual technical and tactical specifications in defensive and offensive phases. The athlete evaluates and considers his/her opponent during the competition to be successful in attaining points and winning through applying an appropriate and accurate strategy (1). Recent statistics indicate that about 50 million persons from all over the world from 191 national federations registered in the World Karate Federation (WKF) are currently active in this sport. Because of some alterations in refereeing rules during the last years, karate is considered a more well-favored and attractive sport among the media and people and was thus selected as a sport has a great attendance potential in the Olympic Games in the year 2008, and consequently, it received the permit from the International Olympic Committee in the year 2016 to be added to the list of Olympic Sports in the Olympic Games 2020 to be conducted at Tokyo, Japan. Adult athletes engage in combat during a 3-minute competition and proceed to the next stage by winning the competition. The athlete gains point by attacking a permitted part of the opponent's body and is scored for the same. The basic specification of karate that makes it

*. Corresponding Author:

Yaping Zhong, Professor

E-mail: zhongyaping@whsu.edu.cn 
different from other combat sports is the evident technique in distinguishing the points (2). The body parts and types of attacks will specify the type of point. Punches to the trunk and face earn one point to the competitor (World Karate Federation). Kicks to the trunk earn two points and those to the head and face earn three points, and there is a three-point attack when a competitor upsets the opponent's balance using his/her feet and knocks the opponent down and punches one scoring part (Ashi Barai). Each competitor is permitted to have 3 warnings and is disqualified from the competition after the fourth warning; in the case of an 8-point difference between two competitors, the competitor with higher points wins (see from URL: http://www.wkf.net). During the past few years, some studies analyzing athletes' performances in different sports fields have been developed. This analysis of athletic skills is very valuable in helping the coaches improve the athletes' performance, thus increasing their chance of success. Exact and accurate interpretation of the analysis data helps the coaches submit appropriate feedback to the athletes and evaluate their progress during their exercise season, thus providing them valuable insight on the competitors' weaknesses and strengths during their exercise (WKF). A karate competition has two parts: form or Kata and combat or Kumite. A few types of research have been conducted in the domain of Karate competitions (Kumite). Previous studies in combat sports have been done on Kata biomechanics and basic techniques $(3,4)$, on injuries $(5,6)$, on psychology $(7,8)$, and physiology $(9,10)$. Beekley and Tabben noted that performance specification does not depend on combat sports and that winning and success need a combination of technique, power, aerobic fitness, and speed $(11,12)$. Therefore, it is known that without an accurate study of the technical demands that have been imposed on an athlete during a competition, it will be unlikely that he/she will progress through with all his/her power. Koropanovski and Jovanovic analyzed 55 combats in the year 2007 and saw that the scoring technique most often used was the Gia Kuzuki technique (34.91\%) (2). Research in the year 2009 by Laird and McLeod showed that Gia Kuzuki was still the highest scoring technique (43.28\%) (13). In the year 2020, research done by Alinaghipour and Zareian indicated that kizama tesuki was the highest-scoring technique in the World Championship Games 2016 (14). Koropanovski and Jovanovic, in the year 2007, found that the highest frequency in attacks was by using the Gia Kuzuki and Kizama tesuki (2) techniques. Therefore, owing to the presence of a relatively few numbers of studies in the field of Karate on the special conditions of the combat (15) and also contradictions in the results obtained in these studies, combined with the changes in referring rules during the last years, new studies taking into account the new rules in combat competitions (Kumite) are required. Meanwhile, the problem of successfully designing and modeling exercises and competitions without an accurate analysis of the activity may not be solved (16). There has not been a serious, constant, and distinct system in Karate for observing and analysing sport combats that could provide a complete recognition of the technical and tactical particulars of the opponents. Thus, the present research studies 25 World Champions in the years 2018 and 2019, including those who won the gold, silver, and bronze medals, in 5 different weight groups using the rules of the World Karate Federation. This study provides data and information for coaches when recommending or designing a more efficient exercise plan in order to achieve higher standards and contribute in providing reliable and targeted operational standards.

\section{MATERIALS AND METHODS}

Participants. This study was done to determine the World Top Athletes' Particulars in the World Leagues Competitions and the World Championship in the years 2018 and 2019 using the video analysis technology.

Data Analysis. Video Analysis methods having real recordable data with the possibility for slow-motion analysis were used in this study to accurately distinguish the techniques. The statistical sample consisted of 25 top karate athletes in the first to the fifth weight ranks (-60, $-67,-75,-84$, and +84), and the different techniques used by the World Champions were studied and evaluated using the Video Analyser along with Excel 2015.

Data Acquisition and Performance Parameters. Case study items were the hand techniques, feet techniques, attack number, and number of defensive attacks to the permitted parts 
of the body to gain points (head, face, trunk, back). Also, the techniques must be characterized by good form, enough speed, timing, suitable distance, and power control of the hit in the head and face to gain points (World Karate Federation 2019). We observed 11 types of attacks (Table 1).

\section{RESULTS}

Numerical and percentage analysis for each one of the technical and tactical factors were fulfilled in real combat, and the results are indicated in different tables.

What percentage of the total attacks by 25 top athletes of the world in 118 competitions were scoring attacks? (Table 2) Considering the table above, it can be observed that 192 out of the 602 attacks $(31.90 \%)$ were successful while 410 attacks $(68.10 \%)$ were unsuccessful in gaining points, according to the results of the $\chi 2$ test; the frequency difference between successful and unsuccessful attacks was statistically significant $(\mathrm{P}<0.01)$.

What percentage of the total attacks by the 25 world top athletes in the 118 competitions analyzed has been carried out using the hands and feet? (Table 3) Considering the table above, it can be observed that 422 attacks out of 602 attacks (70.1\%) were done using hands and 180 attacks (29.9\%) were carried out with the feet, and the difference was statistically significant $(\mathrm{P}<0.01)$.

What percentage of total attacks by the 25 top athletes of the world in 118 competitions touched the head and trunk of the opponents? (Table 4) Considering the table above, it can be observed that 462 attacks out of $602(76.7 \%)$ were to the head and 140 attacks $(23.3 \%)$ were to the trunk of the opponent, and the difference between the hits to the head and trunk was statistically significant $(\mathrm{P}<0.01)$.

Attacks alternation in 180 seconds of the competition (Table 5). Considering the table above, it can be observed that 111 attacks of 602 attacks (18.4\%) were done in the first 60 seconds of the competition, 210 attacks $(34.90 \%)$ were done in the second minute, and 281 attacks $(46.7 \%)$ were done in the last 60 seconds of the competition; the difference was statistically significant in this case as well $(\mathrm{P}<0.01)$.

What has been the reaction of the 25 top athletes to attacks by the opponent? (Table 6) Considering the table above, it can be observed that out of the 469 attacks by the opponents, 35 reactions $(7.5 \%)$ were a defense, and 4 reactions $(0.9 \%)$ were defense and hit. One hundred and forty-seven reactions $(31.3 \%)$ were counterattacks, 86 reactions $(18.3 \%)$ could not be done due to the attack speed of the opponents, 146 reactions $(31.1 \%)$ were to dodge the opponents' attack, and 51 reactions (10.9\%) were to dodge and attack against the opponents' attack. Thus, the highest reactions to the opponents' attacks were counterattacks and dodging. The difference between the reactions was statistically significant $(\mathrm{P}<0.01)$.

The frequency of the techniques used in attacks by world champions (Table 7). Considering the table above, we observed that out of the 11 types of attacks used, the frequently used ones were attack No. 8 , with a success percentage of $45.45 \%$, attack No. 3, with a success percentage of $44.62 \%$, followed by the other attacks (Nos. 1, 5, 4, 2, 7, 11, 10, 6 and 9). The difference in the success of the attacks was significant $(\mathrm{P}<0.01)$. Therefore, it can be concluded that attack types No. 3 and 8 were the most successful types of attack, while attacks type No. 6 and 9 were the most unsuccessful.

Table 1. Descriptive the Techniques Used to Score in Karate World Championships

\begin{tabular}{lc}
\hline Japanese Name List & English Name List \\
\hline Kizametsuki & Jab punch \\
\hline uraken & Back fist \\
\hline Gia kuzuki & Reverse punch \\
\hline Kizametsuki \& Gia & Jab punch \& reverse \\
kuzuki & punch \\
Oi tesuki & Lunge punch \\
\hline Mawashigeri & Roundhouse kick \\
\hline Ura Mawashigeri & Hook kick \\
\hline Ashi barai & Foot sweep \\
Ke kume & Sidekick \\
\hline Ushiru geri & Back kick \\
Combination & Hands and kick \\
\hline
\end{tabular}

Table 2. Percentage of Successful and Unsuccessful Attacks Performed by World Champions

\begin{tabular}{lccccc}
\hline Type of Attack & Frequency & Percent & Chi-Square & df & Sig \\
\hline Successful & 192 & $31.9 \%$ & 17.94 & 1 & 0.001 \\
Unsuccessful & 410 & $68.1 \%$ & & & \\
Total & 602 & & & & \\
\hline
\end{tabular}


Table 3. Frequency of Techniques Performed by Hands and Feet

\begin{tabular}{lccccc}
\hline Type of Attack & Frequency & Percent & Chi-Square & df & Sig \\
\hline Hands & 422 & $70.1 \%$ & 23.29 & 1 & 0.001 \\
Feet & 180 & $29.9 \%$ & & & \\
Total & 602 & & & & \\
\hline
\end{tabular}

Table 4. Frequency of Attacks Performed by World Champions to Opponents' Head and Trunk

\begin{tabular}{lccccc}
\hline Type of Target & Frequency & Percent & Chi-Square & df & Sig \\
\hline Head & 462 & $76.7 \%$ & 31.23 & 1 & 0.001 \\
Trunk & 140 & $23.3 \%$ & & & \\
Total & 602 & & & & \\
\hline
\end{tabular}

Table 5. Frequency of Attacks Performed by World Champions in 180 Seconds of the Competition

\begin{tabular}{lccccc}
\hline Attack Time & Frequency & Percent & Chi-Square & df & Sig \\
\hline The first minute & 111 & $18.4 \%$ & 17.66 & 2 & 0.001 \\
The second minute & 210 & $34.9 \%$ & & \\
The third minute & 281 & $46.7 \%$ & & \\
Total & 602 & & & & \\
\hline
\end{tabular}

Table 6. Frequency of Reaction of World Champions to Opponents' Attack

\begin{tabular}{|c|c|c|c|c|c|}
\hline Reaction to Attacks & Frequency & Percent & Chi-Square & df & Sig \\
\hline Defence & 35 & $7.5 \%$ & 37.92 & 5 & 0.001 \\
\hline Defence and hit & 4 & $0.9 \%$ & & & \\
\hline Counter attacked & 147 & $31.3 \%$ & & & \\
\hline Did not have any reaction & 86 & $18.3 \%$ & & & \\
\hline Dodged & 146 & $31.1 \%$ & & & \\
\hline Dodged and attacked & 51 & $10.9 \%$ & & & \\
\hline Total & 469 & & & & \\
\hline
\end{tabular}

Table 7. Frequency of Sored Techniques

\begin{tabular}{|c|c|c|c|c|c|c|c|}
\hline Type of Attack & Frequency & Successful & Unsuccessful & Success Percentage & Chi-Square & df & Sig \\
\hline 1 & 177 & 64 & 113 & $36.16 \%$ & 9.23 & 10 & 0.001 \\
\hline 2 & 13 & 4 & 9 & $30.77 \%$ & & & \\
\hline 3 & 65 & 29 & 36 & $44.62 \%$ & & & \\
\hline 4 & 92 & 30 & 62 & $32.61 \%$ & & & \\
\hline 5 & 57 & 20 & 37 & $35.09 \%$ & & & \\
\hline 6 & 97 & 17 & 80 & $17.53 \%$ & & & \\
\hline 7 & 27 & 8 & 19 & $29.63 \%$ & & & \\
\hline 8 & 11 & 5 & 6 & $45.45 \%$ & & & \\
\hline 9 & 7 & 1 & 6 & $14.29 \%$ & & & \\
\hline 10 & 20 & 5 & 15 & $25 \%$ & & & \\
\hline 11 & 36 & 9 & 27 & $25 \%$ & & & \\
\hline
\end{tabular}

\section{DISCUSSION}

One hundred and eighteen competitions in the years 2018 and 2019 were investigated and studied to recognize the distinguishing characteristics among the world karate champions. Each competition was studied based on six variables: percentage of successful attacks compared with the unsuccessful attacks, percentage of attacks to the head and trunk, alternation of the attacks in different times, number of attacks done using the hands and feet, reaction to the attacks by the opponents, and alternation of the different techniques in the attack. In this study, we compared the number of successful and unsuccessful attacks (Table 1) and observed a higher percentage of unsuccessful attacks $(68.1 \%)$ than successful attacks (31.9\%), indicating that point attainment by world champions is not an easy task. There are several reasons for this, such as the unsuitable timing of the attack, opponent's mobility, suitable agility and reaction of the opponent, insufficient speed, and explosion. 
Of the total attacks in this study, $70.1 \%$ were done using hand techniques and $29.9 \%$ by feet techniques, indicating the superiority of hands techniques in the alternation of using them in competitions; this is in accord with the studies by Tabben in 2018 and by Laird in 2009 (13-17). This is because of the short distance between the hands and the opponent (face and trunk) in comparison with the feet. Also, hand techniques are faster to implement in comparison with the feet techniques. As regards the scoring parts in attacks (Table 3), 462 attacks out of 602 (76.7\%) were to the head and 140 attacks (23.3\%) were to the trunk of the opponent; the difference was statistically significant. The head and face are parts with the highest probability to be hit in attacks compared to the trunk because covering and defending these parts need more consideration and exercise due to multiple attacks. Another factor used to determine the intensity and pressure of 180 seconds of the competition is the number of attacks at three different times during a competition. As can be seen from Table 4, 111 attacks (18.4\%) of the total attacks occurred in the first 60 seconds of the competition, 210 attacks (34.9\%) occurred in the second 60 seconds, and 281 attacks $(46.7 \%)$ occurred in the last 60 seconds of the competition, and the difference in times of the competition was significant. Consequently, the highest intensity of competition was at the last minute where the athletes put in their best efforts to win. During the physical preparation period, the coaches and athletes give specific consideration and importance to the last minute of the competition. Reactions of the world karate champions against the opponents' attacks are shown in Table 5 in the present study. Counterattack and dodging are the most usable reactions fulfilled by the world karate champions during competitions. Also, defense and attack had the least alternation among the different reactions, necessitating a separate study. Low alternation of defense and attack reactions may be due to the action of very fast reactions in karate that the athletes do not have sufficient time for two continuous reactions. In this research, we studied 11 different technical models with the highest application under the referees' law in karate competitions and found that kizama tesuki with 177 repetitions had the highest application and ke kume with 7 repetitions had the lowest application. Also, we studied the success percentage of techniques in point attainment in comparison with their repetition. Table 6 shows that attack No. 8, Ashi Barai had a $45.45 \%$ success percentage, technique No. 3, Gia Kuzuki had a $44.62 \%$ success percentage, followed by other techniques are Nos. 1, 5, 4, 2, 7, 11, 10, 6 and 9 (kizama tesuki, Oi-tesuki, kizama tesuki and Gia Kuzuki, uraken, Ura mavashi geri, combined techniques of hands and feet, ushirogi, mawashi geri, keakume). Therefore, we can conclude that attacks No. 8 and 3 are the most successful attacks, and attacks No. 6 and 9 are the least successful. This is in accordance with the research by Pitter Laird and Koropanovski which showed that the Gia Kuzuki technique was the highest-scoring technique $(2,13)$ and with the research by Alinaghipour which found kizama zuki technique as the most scoring technique (14). Also, our research results are contrary to those found by Romanovitch, who found mawashi geri technique as the most applicable technique (18). In this research, kizama zuki had the highest frequency among the techniques studied, but the ratio of repetition of this technique to its scoring is in the third rank. In accordance with the research by Alinaghipour, the lowest scoring technique was mae giri and ushirogri and kea gee. One of the most important factors of success in a sport is information and knowledge about the athletes' activity during the competitions. This research may help coaches design the exercises according to the results observed from the performance analysis of the world karate champions and thus help them provide a training procedure under superior templates. The results of this research may be presented to the coaches and athletes as a technical software.

\section{CONCLUSION}

This study on the performance of 25 top athletes of the world who won the world medals in the years 2018 and 2019 suggests that hand attacks are superior to feet attacks and that attacks to the head lead to higher point attainment compared to those to the trunk. Gia Kuzuki and Ashi Barai techniques are the greatest scoring techniques compared with their repetition frequency among the world champions, and the last 60 seconds of the competition form the most intense time in terms of attack number. Counterattack and dodging are the commonest reactions of the world champions to the opponents' attacks. 


\section{APPLICABLE REMARKS}

This study provides data and information for coaches:

- The last-minute of the competition was the highest intensity time in a three-minute competition (with $46.70 \%$ of attacks happening then).
- The techniques of Ashi Barai and Gia Kuzuki were the most commonly used techniques among the techniques for scoring used by world champions what make the difference between world champions and other players.

\section{REFRENCES}

1. Carlsson T, Berglez J, Koivisto PS, Carlsson M. The impact of video review in karate kumite during a Premier League competition. Int $J$ Performance Anal Sport. 2020;20(5):846-856. doi: 10.1080/24748668.2020.1794258

2. Koropanovski N, Jovanovic S. Model characteristics of combat in elite male karate competitors. Serbian J Sport Sci. 2007;1(3):97-115.

3. Witte K. Biomechanical analysis in karate. Proceed World Congress Performance Anal Sport. 2008;VIII:253-267.

4. Keith S, Urbinati, Agnelo D, Papcke C, Pinheiro R, Eduardo M. Physiological and Biomechanical Fatigue Responses in Karate: A Case Study. Open Sport Sci J. 2017;10(Suppl-2, M10):286-293. doi: 10.2174/1875399X01710010286

5. Arriaza R, Leyes M. Injury profile in competitive karate: prospective analysis of three consecutive World Karate Championships. Knee Surg Sports Traumatol Arthrosc. 2005;13(7):603-607. doi: 10.1007/s00167004-0593-6 pmid: 15678297

6. Ortu M, Vaccarezza M, Trovati S, Galli M, Gervasoni C, Vella A. A martial arts injury: karate induced unilateral haematoma of the adrenal gland. Br J Sports Med. 2006;40(8):730-731; discussion 731. doi: 10.1136/bjsm.2006.026500 pmid: 16723403

7. Ruiz M, Hanin Y. Metaphoric Description and Individualized Emotion Profiling of Performance States in Top Karate Athletes. J Appl Sport Psychol. 2004;16(3):258-273. doi: 10.1080/10413200490498366

8. Thatcher J, Kerr J, Amies K, Day M. A reversal theory analysis of psychological responses during sports injury rehabilitation. J Sport Rehabil. 2007;16(4):343-362. doi: 10.1123/jsr.16.4.343 pmid: 18246901

9. Imamura H, Yoshimura Y, Nishimura S, Nakazawa AT, Teshima K, Nishimura C, et al. Physiological responses during and following karate training in women. J Sport Med Physic Fitness. 2002;42(4):431437. doi: 10.1097/00005768-199902000-00019

10. Beneke R, Beyer T, Jachner C, Erasmus J, Hutler M. Energetics of karate kumite. Eur J Appl Physiol. 2004;92(4-5):518-523. doi: 10.1007/s00421-004-1073-x pmid: 15138826

11. Beekley M, Abe T, Kondo M, Midorikawa T, Yamauchi T. Comparison of normalized maximum aerobic capacity and body composition of sumo wrestlers to athletes in combat and other sports. J Sport Sci Med. 2006;CCSSI:13-20.

12. Tabben M, Sioud R, Haddad M, Franchini E, Chaouachi A, Coquart J, et al. Physiological and Perceived Exertion Responses during International Karate Kumite Competition. Asian J Sports Med. 2013;4(4):263-271. doi: 10.5812/asjsm.34246 pmid: 24800001

13.Laird P, McLeod K. Notational analysis of scoring technique in competitive men's karate. Int J Perform Anal Sport. 2009;9(2):171-187. doi: 10.1080/24748668.2009.11868475

14. Alinaghipour M, Zareian E. Scoring Techniques in Karate Kumite: The Scoring Techniques in the Final Competitions of the Karate World Championships. Ann Appl Sport Sci. 2020;8(2):e760. doi: 10.29252 /aassjournal.760

15. Guzvica M. Analysis of fight outcome of different weight category in Yugoslav karate competitions. Physical culture (Belgrade). 2001;55(1-4):33-41.

16.Petri K, Emmermacher P, Danneberg M, Masik S, Eckardt F, Weichelt S. Training using virtual reality improves response behavior in karate kumite. Int Sport Engin Associat. 2019. doi: 10.1007/s12283-0190299-0

17. Tabben M, Miarka B, Chamari K, Beneke R. Decisive Moment: A Metric to Determine Success in Elite Karate Bouts. Int J Sports Physiol Perform. 2018;13(8):1000-1004. doi: 10.1123/ijspp.2017-0526 pmid: 29345545

18. Romanovitch M. Tactical and technical performance analysis of the male $65 \mathrm{KG}$ category at the brazilian Shotokan karate championship. J Phys Educ. 2020;31:e3106. doi: 10.4025/jphyseduc.v31i1.3106 